Laurence J. C. van Warmerdam - Jaap Verweij

Jan H. M. Schellens • Hilde Rosing • Brian E. Davies

Maureen de Boer-Dennert - Robert A. A. Maes

Jos H. Beijnen

\title{
Pharmacokinetics and pharmacodynamics of topotecan administered daily for 5 days every 3 weeks
}

Received: 25 February 1994 / Accepted: 29 June 1994

\begin{abstract}
Topotecan is a novel semisynthetic derivative of the anticancer agent camptothecin and inhibits the intranuclear enzyme topoisomerase I. The lactone structure of topotecan, which is in equilibrium with the inactive ringopened hydroxy acid, is essential for this activity. The open form predominates at physiological $\mathrm{pH}$. We performed a pharmacokinetic study as part of a phase I study in patients with various types of solid tumors, where topotecan was administered in a 30-min infusion daily on 5 consecutive days every 3 weeks. The plasma kinetics of topotecan could be described best using an open two-compartment model with $t \frac{1}{2}(\alpha)$ and $t 1 / 2(\beta)$ of 8.1 (range 0.3 to 40.7 ) $\mathrm{min}$ and 132 (range 49 to 286 ) min, respectively. The plasma concentration-time profiles of the metabolite, however, could be described using a one-compartment model with $\mathrm{t} 1 / 2$ (formation) of 29.0 (range 5.6-99.5) $\mathrm{min}$ and $\mathrm{t} 1 / 2$ (elimination of 123.2 (range $32-265$ ) min, respectively. The lactone was the predominate form during the first hour from the start of infusion, but was rapidly converted into its ring-opened structure. The elimination rate of topotecan was independent of the dose. There were linear relationships between the dose $\left(\mathrm{mg} \mathrm{m}^{-2} \mathrm{day}^{-1}\right)$, the area under the plasma concentration versus time curve (AUC) of topotecan and its metabolite, the total AUC, peak plasma lactone concentrations, and the time period that the topotecan concentrations remained above $10 \mathrm{n} M$. Different models were used to correlate pharmacokinetic and pharmacodynamic para-
\end{abstract}

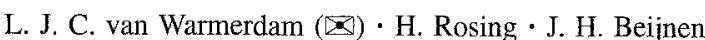

Department of Pharmacy, Slotervaart Hospital and Netherlands Cancer Institute, Louwesweg 6, 1066 EC, Amsterdam, The Netherlands

J. Verweij - J. H. M. Schellens - M. de Boer-Dennert Department of Medical Oncology, Rotterdam Cancer Institute, Rotterdam, The Netherlands

B. E. Davies

Department of Pharmacokinetics, SmithKline Beecham Pharmaceuticals, King of Prussia, USA
}

R. A. A. Maas

Department of Pharmaceutical Analysis and Toxicology, Faculty of Pharmacy, State University of Utrecht, Utrecht, The Netherlands meters. The percentage decrease in absolute neutrophil count (ANC) was related to these parameters and plots were well fitted by linear and sigmoidal $E_{\max }$ models.

Key words Pharmacodynamics $\cdot$ Pharmacokinetics Topotecan - Topoisomerase I inhibitor

\section{Introduction}

Topotecan ([S]-9-dimethylaminomethyl-10-hydroxy-camptothecin hydrochloride, SK\&F 104864-A, NSC 609699), is a novel semisynthetic derivative of camptothecin, an anticancer drug derived from the Asian tree Camptotheca acuminata. Owing to camptothecin's serious and unpredictable gastrointestinal, urothelial and myelosuppressive toxicities, clinical evaluation had to be discontinued in the early 1970s $[18,19]$. Compared with campthothecin, topotecan is more water soluble, has reduced protein binding, and shows promising efficacy with a strongly reduced toxicity profile $[2,6,11,16,22,33]$. The dose-limiting toxicity of topotecan is reversible myelotoxicity, especially granulocytopenia [22, 23, 26, 30, 33], and mucositis [16].

Topotecan and other camptothecin analogues inhibit the intranuclear enzyme topoisomerase I. Topoisomerase I is involved in RNA transcription, DNA replication, and possibly DNA repair and genetic rearrangements $[1,13$, 27]. During the process of winding and unwinding of DNA, torsional stresses and topological problems occur. Topoisomerase enzymes change the conformation of a segment of DNA, resolving these mechanical obstacles [1]. Topotecan and other camptothecin analogues prohibit RNA transcription by stabilizing the DNA-topoisomerase I "cleavable complexes," which can result in lethal DNA damage during the courses of DNA replication [10, 13]. The lactone structure, which is in equilibrium with the open-ring hydroxy acid (SK\&F 105992) at constant $\mathrm{pH}$ is essential for this function (Fig. 1) [11, 31]. The closed lactone ring predominates at acidic $\mathrm{pH}$, but the reverse reaction of the parent into the metabolite predominates at physiological $\mathrm{pH}$ 
<smiles>CCC1(O)C(=O)OCc2c1cc1n(c2=O)Cc2cc3c(CN(C)C)c(O)ccc3nc2-1</smiles>

A

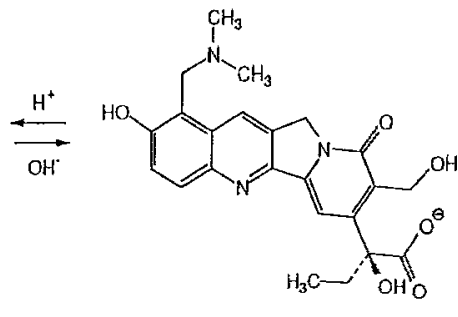

B
Fig. 1 A, B Chemical structures of $\mathbf{A}$ topotecan and $\mathbf{B}$ its lactone ringopened hydroxy acid. Both forms are in equilibrium at constant $\mathrm{pH}$

$[2,28]$. The spontaneous hydrolysis of the parent drug to the inactive form may, therefore, have important pharmacokinetic and pharmacodynamic implications.

Although neutropenia and leukopenia were correlated to pharmacokinetic parameters, such as the AUC and peak plasma $\left(\mathrm{C}_{\max }\right)$ concentrations of topotecan in previous studies, only weak or absent relations were found $[3-5$, $32,33]$.

We performed a pharmacokinetic study as part of a phase I study [30], using a high-performance liquid chromatography [HPLC) procedure developed in our laboratory [2], by which we can measure selectively and simultaneously both topotecan and its lactone ring-opened structure. The pharmacokinetic data have been correlated with the pharmacodynamic outcome of the phase I study by using different mathematical models.

\section{Patients and methods}

\section{Patient population}

The patients, from whom pharmacokinetic curves and clinical history were obtained, participated in a phase I trial of topotecan administered daily for 5 consecutive days every 3 weeks [30]. Eligibility criteria included a histologically confirmed diagnosis of a solid malignant tumor no longer amenable to established forms of treatment. All patients had an acceptable bone marrow function (white blood cells (WBC) $>4 \times 109 / 1$ and platelets $\geq 100 \times 109 / 1)$, serum bilirubin $\leq 26 \mu \mathrm{M}$ and serum creatinine $\leq 140 \mu \mathrm{M}$, with no prior history of hemorrhagic cystitis, WHO performance status $\leq 2$, life expectancy of $\geq 12$ weeks and age $18-75$ years. All patients gave informed consent.

\section{Treatment plan}

Topotecan (SmithKline Beecham, King of Prussia, USA) was supplied as a clear yellow solution, containing the hydrochloride salt. This solution consisted of $2.57 \mathrm{mg}$ of topotecan hydrochloride, equivalent to $2 \mathrm{mg}$ of the free base, $52.1 \mathrm{mg}$ of D-gluconic aicd as its monopotassium salt, hydrochloric acid or sodium hydroxide for adjustment to $\mathrm{pH} 3.0$, and water for injection USP q. s. to give $2.2 \mathrm{ml}$. The appropriate dosage of the drug was diluted in $48 \mathrm{ml}$ of normal saline and administered i. v. by an infusion pump over $30 \mathrm{~min}$ on 5 consecutive days every 3 weeks. Dose escalation was performed according to a modified Fibonacci scheme, using doses of $0.5,0.65,0.9,1,1.25$, and $1.5 \mathrm{mg} \mathrm{m}^{-2}$ day $^{-1}$, respectively. Intrapatient dose escalation was not permitted. To determine the hematological and non-hematological toxicities, patients were evaluated weekly by clinical history, physical examination, senum chemistry and hematology screening. At the highest dose level hematology screening was performed twice a week.

Pharmacokinetic studies

Blood samples ( $5 \mathrm{ml}$ each), taken from an indwelling i.v. cannula placed in the arm contralateral to the arm receiving topotecan, were collected in heparinized tubes at 12 time points: before each infusion, at 5, 10,15 and 30 min during the infusion, and at 15 and $30 \mathrm{~min}$ and $1,2,3,4$, and $6 \mathrm{~h}$ after the end of the 30 -min infusion. Samples were collected during the first and, if possible, during the 4th or 5th day of drug administration. Plasma was obtained by immediate centrifugation $(5 \mathrm{~min} ; 1500 \mathrm{~g}$ ) of the samples, followed by protein precipitation with cold methanol: $1 \mathrm{ml}$ plasma was added to $4 \mathrm{ml}$ of methanol $\left(-30^{\circ} \mathrm{C}\right)$. Thereafter, the substance was mixed and centrifuged ( $5 \mathrm{~min} ; 1500 \mathrm{~g}$ ), and the clear supernatant was transferred to a glass autosampler vial and stored $\left(-30^{\circ} \mathrm{C}\right)$ until analysis. Topotecan and its lactone ring-opened form were determined by a validated HPLC method using fluorescence detection, developed in our laboratory [2]. Using this method both forms are measured selectively and simultaneously in a single run.

The plasma concentration $[C(\mathrm{t})]$ versus time $(t)$ curves of topotecan were analyzed using the pharmacokinetic software package MW/Pharm (MEDNWARE, Groningen, The Netherlands) [21]. This non-linear least-squares, iterative regression program determines slopes and intercepts of the logarithmically plotted curves of multi-exponential functions. Initial estimates of the parameters were determined by an automated curve stripping procedure. In general, the mathematical equation describing plasma drug concentration $C(t)$ at any time $t$ during and after i.v. infusion is given during infusion by:

$C(t)=\sum_{i=1}^{N}\left\{C_{i} /\left(\lambda_{i} \times T_{i n f}\right) \times\left(1-e^{\left(-\lambda_{i} \times t\right)}\right)\right\}$

and post infusion by:

$C(t)=\sum_{i=1}^{N}\left\{C_{i} /\left(\lambda_{i} \times T_{i n f}\right) \times\left(e^{\left(-\lambda_{i} \times\left[t-T_{i n f}\right]\right)}-e^{\left(-\lambda_{i} \times t\right)}\right)\right\}$

where $\lambda_{\mathrm{i}}$ is the exponent of the $i$-th exponential term, $C_{\mathrm{i}}$ is the initial concentration of the $i$-th component of the curve and $T_{\text {inf }}$ is the infusion time.

Topotecan kinetics could be best described by a bi-exponential model $(N=2)$, which gave the lowest Akaike information criterium. Curve fitting with this model yields the parameters $C_{1}, C_{2}, \lambda_{1}$ and $\lambda_{2}$. Respective half-lives were calculated from the equations $t \frac{1}{1} 2(\alpha)=0.693 /$ $\lambda_{1}$ and $t^{1 / 2}(\beta)=0.693 / \lambda_{2}$. The area under the curve (AUC) was determined on the basis of the fitted curve as the exact integral of the $C(t)$ versus $t$ plots $\left(00^{\infty} C(t) d t\right)$ from $t=0$ to infinity. Total plasma clearance $(C L)$ was calculated by dividing the dose by the AUC. The computer program also calculated the apparent first-order elimination rate constant from the central compartment $\left(k_{10}\right)$, the intercompartmental transfer rate constants $k_{12}$ and $k_{21}$, the apparent distribution volume of the central compartment $\left(V_{c}\right)$, and the apparent distribution volume during steady state $\left(V_{\mathrm{ss}}\right)$ from $C_{1}, C_{2}, \lambda_{1}$ and $\lambda_{2}$ with standard equations [7]. The pharmacokinetics of the topotecan metabolite were modelled by a bi-exponential equation describing both the formation and elimination of the metabolite in a one-compartment model:

$C_{m}(t)=C\left(e^{\left(-\lambda_{\varepsilon} \times t\right)}-e^{\left(-\lambda_{f} \times t\right)}\right)$

where $C_{\mathrm{m}}(t)$ is the metabolite concentration at time $t, \lambda_{\mathrm{e}}$ and $\lambda_{\mathrm{f}}$ are apparent first-order rate constants for metabolite elimination and formation, respectively. $C$ is a constant that depends on the values of $\lambda_{e}, \lambda_{\mathrm{f}}$, the apparent volume of distribution of the metabolite $\left(V_{\mathrm{m}}\right)$, the dose of topotecan and $f_{m}$, the fraction of drug converted into the metabolite. Half-lives were calculated from the equations: $t / 2(1)=0.693 / \lambda_{c}$ and $t 1 / 2$ (2) $=0.693 / \lambda_{\text {f. }}$ Other pharmacokinetic parameters were calculated with standard equations in the same manner as for topotecan [7].

The peak plasma concentrations $\left(C_{\max }\right)$ of topotecan and its ringopened form and the time to reach the maximal concentration $\left(T_{\max }\right)$ are observed experimental values. 
Pharmacokinetic-pharmacodynamic relationships

The pharmacodynamics, especially the dose-limiting toxicities, were explored using plots of percentage decrease (\%decr) in WBC and ANC versus the dose $\left(\mathrm{mg} \mathrm{m}^{-2} \mathrm{day}^{-1}\right)$ and pharmacokinetic parameters. Since it has previously been suggested that the time period that the topotecan concentration is above 1 or $10 \mathrm{nM}$, among other parameters, can be important for toxicity [9], we investigated the following pharmacokinetic parameters: the $C_{\max }(\mathrm{n} M)$, the time period that the topotecan concentration is above $1.0 \mathrm{nM}$ or $10 \mathrm{nM}$ topotecan (h), and the AUC $(\mu \mathrm{M} \cdot \min )$ of topotecan, its metabolite, and the sum of both.

The percentage decrease (\%decr) is defined as:

$\%$ decr $=\frac{\text { Pretreatment value }- \text { value of the nadir }}{\text { Pretreatment value }} \times 100 \%$

The data were fitted using a (log-) linear model, a maximum effect $\left(E_{\max }\right)$ model and a sigmoidal maximum effect ( $\operatorname{sig} E_{\max }$ ) model, as described by a modified Hill equation [15, 22].

The linear models were:

$\%$ decr $=a \cdot(P)+b$

$\log (\%$ decr $)=a \cdot(P)+b$

The $E_{\max }$ model was:

$\%$ decr $=\frac{(M E)(P)}{\left(P_{50}\right)+(P)}$

The sigmoidal $E_{\max }$ model was:

\%decr $=\frac{(M E)(P)^{H}}{\left(P_{50}\right)^{H}+(P)^{H}}$

Where $a$ denotes the slope and $b$ the intercept of the linear models, $M E$ denotes the maximal effect, which is 100 (i.e. $100 \%$ decrease), $P$ denotes the value of the pharmacokinetic parameter of interest, $P 50$ the $P$ that results in $50 \%$ of the $M E$, and $H$ denotes the Hill constant, which describes the shape of the curve. In the $E_{\max }$ model the Hill constant is 1. Linear regression analysis was performed to obtain a correlation coefficient $(r)$ and the slope and intercept of the linear model. The computer program NCSS (Number Cruncher Statistical System, Kaysville, Utah, USA, 1992) and Quattro Pro (Borland International, Scotts Valley, Calif., USA, 1992) were used for all calculations.

The performance of the model was evaluated by using the relative root mean square error (\%RMSE) value and its standard error (SE) [25]. The \%RMSE is a measure of precision and is defined as:

RMSE $\%\left[N^{-1} \cdot \sum_{i=1}^{N}\left(p e_{i}\right)^{2}\right]^{1 / 2} \cdot 100 \%$

and the relative $\mathrm{SE}$ is defined as:

$\mathrm{SE} \%\left[(N \cdot(N-1))^{-1} \cdot \sum_{i=1}^{N}\left(\left(p e_{i}\right)^{2}-\mathrm{RMSE}\right)^{2}\right]^{1 / 2} \cdot 100 \%$

where $N$ is e.g. the number of $P$-pairs (i.e., true with predicted values), and $p e$ is the prediction error $\left[\operatorname{In}\left(P_{\text {true value }}\right)-\operatorname{In}\left(P_{\text {predicted }}\right)\right]$. The smaller the \%RMSE, the better the relation is described by the model. In the most predictive model the RMSE\% approaches zero.

\section{Results}

\section{Pharmacokinetics}

A total of 48 patients, with a variety of malignant solid tumors were entered in the original phase I study [30]. Median age was 56 years (range 25-75), median perfor-

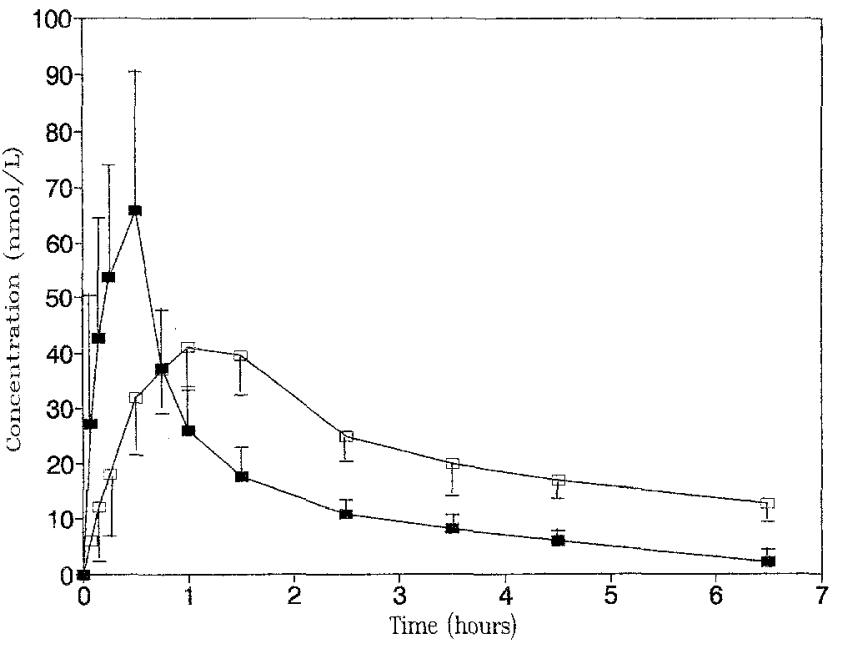

Fig. 2 Average plasma concentration-time curves of topotecan and the lactone ring-opened metabolite $(\square)$ with their standard deviation at a dosage of $1.5 \mathrm{mg} \mathrm{m}^{-2}$ day $^{-1}$

mance status 1 (range $0-2$ ); most patients were pretreated (75\%). Complete plasma concentration time plots were obtained from 19 patients, and from 15 both on day 1 and on day 4 or 5 . All patients were sampled during the first course. Figure 2 depicts the average plasma concentrationtime curves for topotecan and its ring-opened form at a dose of $1.5 \mathrm{mg} / \mathrm{m}^{2}$; the shapes of curves at other dose were similar.

The pharmacokinetics of topotecan could be described best with an open two-compartment model. The pharmacokinetic parameters obtained by means of this model are presented in Table 1.

After cessation of the infusion, the topotecan curves exhibited a bi-exponential decay. The mean values and ranges $(n=34)$ for the linear segments were $t 1 / 2(\alpha)$ : $8.1 \mathrm{~min}$ (range $0.3-40.7 \mathrm{~min}$ ) and $\mathrm{t} 1 / 2(\beta): 132 \mathrm{~min}$ (range 49-286 $\mathrm{min}$ ). The mean values for the compartmental rate constants were: $\mathrm{k}_{10}: 6.6$ (range $\left.0.75-66.6\right) \times 10^{-2} \mathrm{~min}^{-1}, \mathrm{k}_{12}$ : 19.5 (range $0.62-179.5$ ) $\times 10^{-2} \mathrm{~min}^{-1}$ and $\mathrm{k}_{21}$ : 1.81 (range $0.51-6.0) \times 10^{-2} \mathrm{~min}^{-1}$. The mean $\pm \mathrm{SD}$ for the ratio $\mathrm{k}_{21} /$ $\mathrm{k}_{12}$ was $0.32 \pm 0.24$. The apparent distribution volumes of topotecan were $\mathrm{V}_{\mathrm{c}}$ : 17.0 (range 0.8 to 57.7 ) $1 / \mathrm{m}^{2}$, and apparent distribution volume at steady state, $\mathrm{V}_{\mathrm{ss}}: 72.7$ (range $28.5-123.5$ ) $1 / \mathrm{m}^{2}$. The ratio $\lambda_{2} / \mathrm{k}_{10}$ was $0.17 \pm 0.13$. The mean total body clearance of topotecan was 0.57 (range 0.25-0.99) $1 \mathrm{~min}^{-1} \mathrm{~m}^{-2}$. Concentrations above $10 \mathrm{n} M$ were maintained for a median of $1.8 \mathrm{~h}$ (range $0.8-3.2 \mathrm{~h}$ ). The mean percentage of total drug excreted in the urine over the first $24 \mathrm{~h}$ on the 1 st day of the 5 -day course was $25.8 \%$ (range $7.0-58.6 \%$ ). Peak plasma concentrations of topotecan were reached at the end of the 30-min infusion and ranged between 24.8 and $169.8 \mathrm{nM}$. Most pharmacokinetic parameters failed to show dose-related trends $(r<0.25)$, exceptions being $C_{\max }(r=0.44)$, the AUC of topotecan $(r=0.66)$, and the duration of concentrations over $10 \mathrm{n} M$ $(r=0.78)$.

In the first plasma samples the topotecan ring-opened form was already detectable. About $1 \mathrm{~h}$ after the start of the 
Table 1 Pharmacokinetics of topotecan. (Pat. patient number with the $1 \mathrm{~min}^{-1} \mathrm{~m}^{-2} ; t>10 \mathrm{nM}$ time (h) above a concentration of $10 \mathrm{n} M$; $U_{\text {excr: }}$ day of the course in round brackets; Dose $\mathrm{mg} \mathrm{m}^{-2}$ day- $; C_{\max } \mathrm{n} M ; A U C$ total drug urinary excretion over the first $24 \mathrm{~h}$, given as percentage of $\mu \mathrm{M} \cdot \min ; t / 2(\alpha), t^{1 / 2}(\beta) \min ; k_{l o}, k_{12, k 2 l} 10^{-2} \mathrm{~min}^{-1} ; V_{c}, \mathrm{~V}_{\mathrm{ss}} 1 / \mathrm{m}^{2} ; C L \quad$ the administered total dose on 1 day; n.d. not done)

\begin{tabular}{|c|c|c|c|c|c|c|c|c|c|c|c|c|c|}
\hline Pat. & Dose & $\mathrm{C}_{\max }$ & $\mathrm{AUC}$ & $t 1 / 2(\alpha)$ & $\mathrm{t}^{1 / 2}(\beta)$ & $\mathrm{k}_{10}$ & $\mathrm{k}_{12}$ & $\mathrm{k}_{21}$ & $\mathrm{~V}_{\mathrm{c}}$ & $\mathrm{V}_{\mathrm{ss}}$ & $\mathrm{CL}$ & $\mathrm{t}>10 \mathrm{nM}$ & $\mathrm{U}_{\text {excr. }}$ \\
\hline $\begin{array}{l}1(1) \\
1(4) \\
2(1) \\
2(5)\end{array}$ & $\begin{array}{l}0.5 \\
0.5 \\
0.5 \\
0.5\end{array}$ & $\begin{array}{l}45.2 \\
38.6 \\
24.3 \\
27.6\end{array}$ & $\begin{array}{l}2.03 \\
2.74 \\
2.71 \\
2.99\end{array}$ & $\begin{array}{l}4.8 \\
1.9 \\
7.6 \\
1.2\end{array}$ & $\begin{array}{r}69 \\
76 \\
133 \\
149\end{array}$ & $\begin{array}{r}7.20 \\
13.40 \\
2.76 \\
8.02\end{array}$ & $\begin{array}{r}6.11 \\
22.38 \\
5.15 \\
45.95\end{array}$ & $\begin{array}{l}2.01 \\
2.55 \\
1.72 \\
3.29\end{array}$ & $\begin{array}{r}7.4 \\
3.0 \\
14.6 \\
4.6\end{array}$ & $\begin{array}{l}30.1 \\
29.2 \\
58.1 \\
68.3\end{array}$ & $\begin{array}{l}0.53 \\
0.40 \\
0.41 \\
0.37\end{array}$ & $\begin{array}{l}0.85 \\
1.0 \\
1.2 \\
1.0\end{array}$ & $\begin{array}{l}23.6 \\
\text { n.d. } \\
33.9 \\
\text { n.d. }\end{array}$ \\
\hline Mean & & 33.9 & 2.62 & 3.9 & 107 & 7.85 & 19.90 & 2.39 & 7.40 & 46.4 & 0.43 & 1.0 & 28.8 \\
\hline $\begin{array}{l}3(1) \\
3(4) \\
4(1) \\
4(4)\end{array}$ & $\begin{array}{l}0.65 \\
0.65 \\
0.65 \\
0.65\end{array}$ & $\begin{array}{l}22.8 \\
23.7 \\
42.7 \\
32.6\end{array}$ & $\begin{array}{l}2.10 \\
2.48 \\
3.68 \\
1.91\end{array}$ & $\begin{array}{r}8.5 \\
11.3 \\
5.0 \\
12.9\end{array}$ & $\begin{array}{l}167 \\
203 \\
154 \\
126\end{array}$ & $\begin{array}{l}3.00 \\
2.08 \\
4.77 \\
2.68\end{array}$ & $\begin{array}{l}4.40 \\
3.39 \\
8.13 \\
2.15\end{array}$ & $\begin{array}{l}1.11 \\
1.00 \\
1.29 \\
1.10\end{array}$ & $\begin{array}{c}23.1 \\
28.2 \\
8.18 \\
27.6\end{array}$ & $\begin{array}{r}114.0 \\
123.5 \\
58.9 \\
81.7\end{array}$ & $\begin{array}{l}0.69 \\
0.59 \\
0.39 \\
0.74\end{array}$ & $\begin{array}{l}0.75 \\
0.90 \\
1.4 \\
1.1\end{array}$ & $\begin{array}{l}13.8 \\
\text { n.d. } \\
10.6 \\
\text { n.d. }\end{array}$ \\
\hline Mean & & 30.5 & 2.54 & 9.4 & 163 & 3.13 & 4.52 & 1.13 & 21.8 & 94.5 & 0.60 & 1.0 & 12.2 \\
\hline $\begin{array}{l}5(1) \\
5(4) \\
6(1) \\
7(1) \\
7(4) \\
8(1) \\
9(1)\end{array}$ & $\begin{array}{l}0.9 \\
0.9 \\
0.9 \\
0.9 \\
0.9 \\
0.9 \\
0.9\end{array}$ & $\begin{array}{r}51.0 \\
55.1 \\
59.8 \\
42.7 \\
39.7 \\
45.0 \\
156.1\end{array}$ & $\begin{array}{l}3.85 \\
3.72 \\
3.17 \\
2.96 \\
3.09 \\
2.49 \\
8.15\end{array}$ & $\begin{array}{r}1.1 \\
6.0 \\
4.0 \\
8.6 \\
5.0 \\
15.5 \\
8.6\end{array}$ & $\begin{array}{r}89 \\
117 \\
49 \\
132 \\
132 \\
139 \\
99\end{array}$ & $\begin{array}{r}17.80 \\
5.39 \\
7.54 \\
4.08 \\
5.27 \\
1.56 \\
3.06\end{array}$ & $\begin{array}{r}43.10 \\
5.48 \\
8.04 \\
3.47 \\
7.65 \\
1.97 \\
3.89\end{array}$ & $\begin{array}{l}2.76 \\
1.27 \\
3.26 \\
1.04 \\
1.37 \\
1.44 \\
1.87\end{array}$ & $\begin{array}{r}2.9 \\
9.8 \\
8.2 \\
19.4 \\
4.6 \\
42.6 \\
21.0\end{array}$ & $\begin{array}{r}47.7 \\
52.1 \\
28.5 \\
84.0 \\
30.2 \\
101.2 \\
64.8\end{array}$ & $\begin{array}{l}0.51 \\
0.53 \\
0.62 \\
0.79 \\
0.25 \\
0.66 \\
0.64\end{array}$ & $\begin{array}{l}1.5 \\
1.3 \\
1.4 \\
1.4 \\
1.5 \\
1.0 \\
2.9\end{array}$ & $\begin{array}{l}29.1 \\
\text { n.d. } \\
38.0 \\
23.3 \\
\text { n.d. } \\
\text { n.d. } \\
\text { n.d. }\end{array}$ \\
\hline Mean & & 64.2 & 3.92 & 7.0 & 108 & 6.39 & 10.5 & 1.85 & 15.5 & 58.4 & 0.57 & 1.8 & 30.1 \\
\hline $\begin{array}{l}10(1) \\
10(4)\end{array}$ & $\begin{array}{l}1.0 \\
1.0\end{array}$ & $\begin{array}{l}43.8 \\
98.2\end{array}$ & $\begin{array}{l}2.87 \\
7.39\end{array}$ & $\begin{array}{r}12.7 \\
6.4\end{array}$ & $\begin{array}{l}192 \\
129\end{array}$ & $\begin{array}{l}2.67 \\
3.63\end{array}$ & $\begin{array}{l}2.41 \\
6.07\end{array}$ & $\begin{array}{l}0.74 \\
1.59\end{array}$ & $\begin{array}{r}28.4 \\
8.1\end{array}$ & $\begin{array}{r}121.1 \\
39.1\end{array}$ & $\begin{array}{l}0.76 \\
0.30\end{array}$ & $\begin{array}{l}1.1 \\
2.8\end{array}$ & $\begin{array}{l}24.9 \\
\text { n. d. }\end{array}$ \\
\hline Mean & & 71.0 & 5.13 & 9.6 & 161 & 3.15 & 4.24 & 1.17 & 18.3 & 80.1 & 0.53 & 2.0 & 24.9 \\
\hline $\begin{array}{l}11(1) \\
11(4) \\
12(1) \\
12(4) \\
13(1) \\
13(5) \\
14(1) \\
14(4)\end{array}$ & $\begin{array}{l}1.25 \\
1.25 \\
1.25 \\
1.25 \\
1.25 \\
1.25 \\
1.25 \\
1.25\end{array}$ & $\begin{array}{l}67.0 \\
90.4 \\
27.2 \\
44.2 \\
51.7 \\
90.8 \\
43.6 \\
52.3\end{array}$ & $\begin{array}{l}5.12 \\
6.05 \\
2.74 \\
3.81 \\
4.32 \\
4.18 \\
4.18 \\
4.02\end{array}$ & $\begin{array}{l}0.3 \\
5.8 \\
1.0 \\
9.3 \\
5.4 \\
5.9 \\
6.3 \\
4.2\end{array}$ & $\begin{array}{r}94 \\
109 \\
73 \\
93 \\
133 \\
125 \\
109 \\
111\end{array}$ & $\begin{array}{c}66.6 \\
5.2 \\
11.1 \\
2.14 \\
5.61 \\
4.85 \\
3.80 \\
5.12\end{array}$ & $\begin{array}{c}171.8 \\
5.88 \\
53.9 \\
3.50 \\
6.57 \\
6.09 \\
5.98 \\
9.91\end{array}$ & $\begin{array}{l}2.66 \\
1.46 \\
6.00 \\
2.59 \\
1.19 \\
1.35 \\
1.83 \\
2.01\end{array}$ & $\begin{array}{r}0.8 \\
8.7 \\
8.9 \\
33.2 \\
11.4 \\
13.6 \\
17.2 \\
13.3\end{array}$ & $\begin{array}{l}52.4 \\
43.8 \\
89.1 \\
78.1 \\
74.1 \\
75.2 \\
73.4 \\
78.7\end{array}$ & $\begin{array}{l}0.54 \\
0.45 \\
0.99 \\
0.71 \\
0.64 \\
0.66 \\
0.66 \\
0.68\end{array}$ & $\begin{array}{l}2.2 \\
2.3 \\
1.6 \\
2.0 \\
1.4 \\
1.5 \\
1.8 \\
1.8\end{array}$ & $\begin{array}{l}30.8 \\
\text { n.d. } \\
24.1 \\
\text { n.d. } \\
58.6 \\
\text { n.d. } \\
21.0 \\
\text { n.d. }\end{array}$ \\
\hline Mean & & 58.4 & 4.30 & 4.8 & 106 & 13.0 & 32.9 & 2.39 & 13.4 & 70.6 & 0.67 & 1.8 & 33.6 \\
\hline $\begin{array}{l}15(1) \\
15(4) \\
16(1) \\
16(4) \\
17(1) \\
17(4) \\
18(1) \\
18(4) \\
19(1)\end{array}$ & $\begin{array}{l}1.5 \\
1.5 \\
1.5 \\
1.5 \\
1.5 \\
1.5 \\
1.5 \\
1.5 \\
1.5\end{array}$ & $\begin{array}{r}99.0 \\
92.6 \\
100.1 \\
53.3 \\
53.0 \\
81.9 \\
83.4 \\
34.9 \\
62.2\end{array}$ & $\begin{array}{l}9.08 \\
8.39 \\
9.45 \\
6.81 \\
6.40 \\
6.31 \\
5.47 \\
4.15 \\
4.34\end{array}$ & $\begin{array}{r}21.6 \\
40.7 \\
15.5 \\
8.5 \\
2.9 \\
0.3 \\
15.5 \\
5.1 \\
6.3\end{array}$ & $\begin{array}{r}168 \\
286 \\
228 \\
177 \\
126 \\
133 \\
124 \\
77 \\
156\end{array}$ & $\begin{array}{l}1.45 \\
0.81 \\
1.74 \\
2.51 \\
7.66 \\
0.75 \\
1.39 \\
4.15 \\
3.71\end{array}$ & $\begin{array}{c}1.26 \\
0.62 \\
2.26 \\
4.77 \\
15.4 \\
179.5 \\
1.83 \\
7.37 \\
6.49\end{array}$ & $\begin{array}{l}0.91 \\
0.51 \\
0.77 \\
1.27 \\
1.74 \\
1.78 \\
1.80 \\
2.94 \\
1.33\end{array}$ & $\begin{array}{r}27.0 \\
42.6 \\
27.6 \\
20.4 \\
6.9 \\
0.8 \\
57.7 \\
18.4 \\
9.5\end{array}$ & $\begin{array}{r}64.3 \\
95.0 \\
108.0 \\
97.0 \\
68.1 \\
83.0 \\
116.0 \\
64.7 \\
79.2\end{array}$ & $\begin{array}{l}0.39 \\
0.35 \\
0.48 \\
0.51 \\
0.53 \\
0.61 \\
0.80 \\
0.76 \\
0.35\end{array}$ & $\begin{array}{l}3.2 \\
3.0 \\
2.7 \\
2.4 \\
2.8 \\
2.5 \\
2.2 \\
2.3 \\
2.7\end{array}$ & $\begin{array}{l}32.2 \\
\text { n.d. } \\
20.2 \\
\text { n.d. } \\
7.0 \\
\text { n.d. } \\
22.3 \\
\text { n.d. } \\
\text { n.d. }\end{array}$ \\
\hline Mean & & 73.4 & 6.71 & 12.9 & 164 & 2.69 & 24.4 & 1.45 & 23.4 & 86.1 & 0.53 & 2.6 & 20.4 \\
\hline
\end{tabular}

infusion the concentration exceeded the topotecan concentration and declined in parallel with topotecan (Fig. 2). The pharmacokinetic profiles of the lactone ring-opened form of topotecan could be modelled by Eq. (3), which described both the rates of formation and the elimination of the metabolite in a one-compartment model. The model involved constant rate drug formation and elimination both restricted to one compartment. The pharmacokinetic characteristics of the metabolite are summarized in Table 2. Maximal plasma concentrations were reached at $t=47.6$ (range 21-102) min, i.e. about $20 \mathrm{~min}$ after the end of the infusion. The mean half-life $\mathrm{t}^{1 / 2}(2)$, calculated from the terminal linear phase of the metabolite curve, was 123.2 (range $32-265$ ) $\mathrm{min}$ and $\mathrm{t}^{1} / 2(1)$, the mean half-life of the initial phase of the curve, was 29.0 (range 5.6-99.5) min.
The apparent distribution volume of the metabolite was 15.3 (range 1.9-64.5) $1 / \mathrm{m}^{2}$ and the mean total clearance was 0.4 (range $0.17-1.57$ ) $1 \mathrm{~min}^{-1} \mathrm{~m}^{-2}$. Linear regression analysis of $\mathrm{C}_{\max }$ and AUC of the metabolite versus the dose $\left(\mathrm{mg} \mathrm{m}^{-2}\right.$ day $^{-1}$ ) of topotecan shows relationships with $r=0.66$ and $r=0.75$, respectively. Linear regression analysis of the total AUC (lactone + hydroxy acid) versus the dose ( $\mathrm{mg} \mathrm{m}^{-2}$ day $^{-1}$ ) of topotecan shows a linear relationship with $r=0.78$. The other parameters show no dose-related trends. There is, however, a linear relationship between the AUC of topotecan and the AUC of its lactone ringopened form $(r=0.69)$.

Figure 3 shows the mean ratio between the concentration of the parent and ring-opened metabolite (lactone/hydroxy acid) as a function of time with its $95 \%$ confidence interval. 
Table 2 Pharmacokinetics of topotecan's metabolite. (Pat. patient number with the day of course in round brackets; Dose $\mathrm{mg} \mathrm{m}^{-2}$ day $^{-1} ; C_{\max }(\mathrm{nM})$ reached at time $T_{\max }(\min ) ; A U C \mu \mathrm{M}$. $\min ; t^{t / 2}(1), t^{t / 2}(2) \min ; f_{m}$ fraction of topotecan converted into the metabolite; $V_{m} / f_{m} 1 / \mathrm{m}^{2} ; C L f_{m}$ $1 \mathrm{~min}^{-1} \mathrm{~m}^{-2}$ )

\begin{tabular}{|c|c|c|c|c|c|c|c|c|}
\hline Pat. & Dose & $\mathrm{C}_{\max }$ & $\mathrm{T}_{\max }$ & AUC & $\mathrm{t} 1 / 2(1)$ & $\mathrm{t} 1 / 2(2)$ & $\mathrm{V}_{\mathrm{m}} / \mathrm{f}_{\mathrm{m}}$ & $\mathrm{CL} / \mathrm{f}_{\mathrm{m}}$ \\
\hline $1(1)$ & 0.5 & 19.8 & 21 & 1.26 & 10.7 & 37 & 13.4 & 0.87 \\
\hline $1(4)$ & 0.5 & 8.0 & 31 & 2.52 & 10.2 & 113 & 6.3 & 0.43 \\
\hline $2(1)$ & 0.5 & 9.42 & 31 & 0.69 & 28.5 & 32 & 64.5 & 1.57 \\
\hline $2(5)$ & 0.5 & 11.5 & 45 & 2.25 & 5.6 & 186 & 3.9 & 0.48 \\
\hline Mean & & 12.2 & 32 & 1.68 & 13.8 & 92 & 22.0 & 0.84 \\
\hline $3(1)$ & 0.65 & 10.1 & 102 & 3.10 & 33.0 & 126 & 22.0 & 0.47 \\
\hline $3(4)$ & 0.65 & 9.7 & 45 & 2.44 & 27.8 & 107 & 23.7 & 0.59 \\
\hline $4(1)$ & 0.65 & 18.2 & 89 & 7.07 & 61.1 & 94 & 17.6 & 0.20 \\
\hline $4(4)$ & 0.65 & 17.0 & 93 & 2.82 & 50.4 & 55 & 36.3 & 0.50 \\
\hline Mean & & 13.8 & 82 & 3.86 & 43.1 & 96 & 24.9 & 0.44 \\
\hline $5(1)$ & 0.9 & 20.2 & 46 & 4.74 & 12.7 & 134 & 7.5 & 0.41 \\
\hline $5(4)$ & 0.9 & 20.0 & 31 & 3.85 & 12.2 & 125 & 9.0 & 0.51 \\
\hline $6(1)$ & 0.9 & 21.5 & 60 & 6.18 & 27.1 & 130 & 12.5 & 0.32 \\
\hline $7(1)$ & 0.9 & 45.6 & 30 & 7.93 & 20.7 & 63 & 21.3 & 0.71 \\
\hline $7(4)$ & 0.9 & 24.5 & 60 & 6.98 & 7.8 & 144 & 1.9 & 0.17 \\
\hline $8(1)$ & 0.9 & 26.6 & 30 & 2.79 & 34.2 & 108 & 12.3 & 0.25 \\
\hline $9(1)$ & 0.9 & 69.7 & 30 & 11.54 & 22.4 & 141 & 9.4 & 0.29 \\
\hline Mean & & 32.6 & 41 & 6.29 & 19.5 & 121 & 10.6 & 0.38 \\
\hline $10(1)$ & 1.0 & 14.3 & 45 & 3.31 & 32.9 & 98 & 31.3 & 0.66 \\
\hline $10(4)$ & 1.0 & 34.5 & 45 & 7.45 & 19.0 & 118 & 7.9 & 0.29 \\
\hline Mean & & 24.4 & 45 & 5.38 & 26.0 & 108 & 19.6 & 0.48 \\
\hline $11(1)$ & 1.25 & 39.0 & 90 & 16.2 & 8.5 & 265 & 2.1 & 0.17 \\
\hline $11(4)$ & 1.25 & 41.8 & 30 & 13.6 & 19.7 & 180 & 5.7 & 0.20 \\
\hline $12(1)$ & 1.25 & 29.7 & 60 & 6.07 & 8.9 & 137 & 5.8 & 0.45 \\
\hline $12(4)$ & 1.25 & 27.1 & 30 & 5.42 & 32.0 & 81 & 23.0 & 0.50 \\
\hline $13(1)$ & 1.25 & 22.6 & 35 & 4.13 & 16.7 & 100 & 16.2 & 0.67 \\
\hline $13(5)$ & 1.25 & 24.8 & 30 & 4.60 & 23.3 & 111 & 20.1 & 0.60 \\
\hline $14(1)$ & 1.25 & 18.2 & 36 & 4.24 & 22.6 & 109 & 20.8 & 0.64 \\
\hline $14(4)$ & 1.25 & 17.3 & 31 & 4.69 & 18.6 & 131 & 15.6 & 0.58 \\
\hline Mean & & 27.6 & 43 & 7.37 & 18.8 & 139 & 13.7 & 0.48 \\
\hline $15(1)$ & 1.5 & 48.4 & 30 & 11.3 & 64.8 & 76 & 16.8 & 0.36 \\
\hline $15(4)$ & 1.5 & 38.7 & 42 & 9.16 & 99.5 & 118 & 18.7 & 0.26 \\
\hline $16(1)$ & 1.5 & 47.8 & 35 & 12.8 & 41.9 & 161 & 15.7 & 0.26 \\
\hline $16(4)$ & 1.5 & 37.9 & 50 & 12.7 & 64.7 & 90 & 30.8 & 0.33 \\
\hline $17(1)$ & 1.5 & 35.2 & 32 & 9.98 & 15.3 & 203 & 4.2 & 0.19 \\
\hline $17(4)$ & 1.5 & 47.6 & 45 & 17.1 & 9.2 & 179 & 3.0 & 0.23 \\
\hline $18(1)$ & 1.5 & 56.7 & 30 & 14.4 & 85.0 & 96 & 13.3 & 0.25 \\
\hline $18(4)$ & 1.5 & 49.9 & 90 & 13.3 & 28.0 & 184 & 4.2 & 0.24 \\
\hline $19(1)$ & 1.5 & 42.0 & 90 & 13.4 & 9.8 & 156 & 4.0 & 0.28 \\
\hline Mean & & 44.9 & 49 & 12.7 & 46.4 & 140 & 12.3 & 0.27 \\
\hline
\end{tabular}

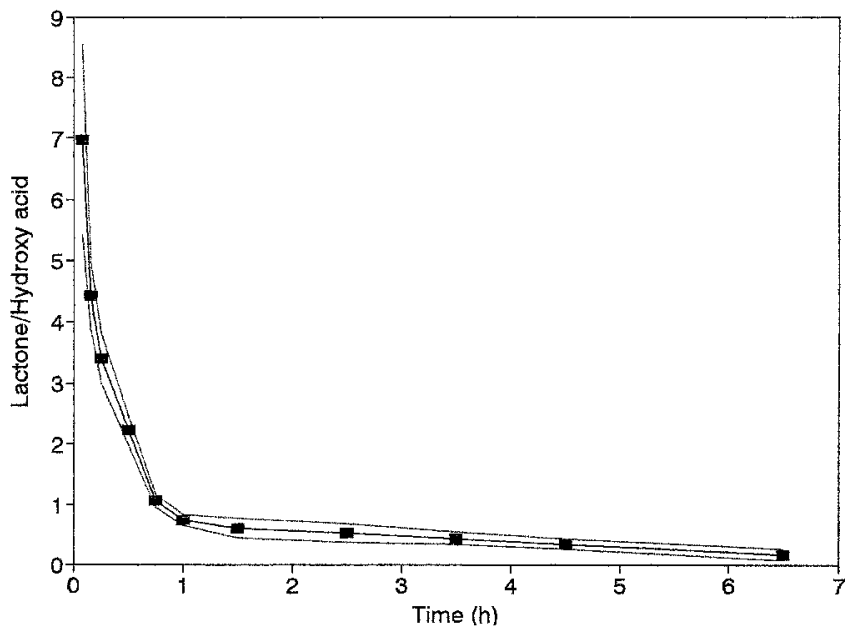

Fig. 3 Mean ratio between plasma concentrations of topotecan and its ring-opened metabolite (lactone/hydroxy acid) as function of time, with its $95 \%$ confidence interval
The ratio declines rapidly from approximately 7 to 1 , followed by a slow decrease to about 0.17 at $6 \mathrm{~h}$ after the start of infusion.

The pharmacokinetic parameters calculated from the analysis on day 1 for each patient are comparable with the values obtained on day 4 or 5 for the same patient (paired Student's $t$-test; $P<0.94$ ). However, in two patients ( 4 and 10; Tables 1,2) large differences in AUC values were observed.

Hematological toxicity

In all 48 patients the main toxicity was myelosuppression, especially granulocytopenia, with $56 \%$ of the evaluable courses resulting in grade 4 granulocytopenia. Thrombocytopenia was much less frequent and less severe (mean nadir $\left.125 \pm 87 \times 10^{9} / 1\right)$. Anemia occurred regularly but was only incidentally severe (average decrease of $16 \% \pm 6 \%$ ). The 
Table 3 Precision of models correlating (log-) \%decr in ANC versus the dose and pharmacokinetic parameters. The precision is evaluated by using the percentage root mean square error (\%RMSE) value and its standard error (SE). The smaller the \%RMSE, the better the relation is described by the model ( $P$ the pharmacokinetic parameter of interest; $r$ correlation coefficient)

\begin{tabular}{|c|c|c|c|c|c|c|c|c|c|c|}
\hline Model: & Line & & & $\log 1$ & & & $\mathrm{E}_{\max }$ & & sigm & \\
\hline$\%$ decrANC = & $\mathrm{a} \cdot \mathrm{P}$ & & & $\begin{array}{l}\log (9 \\
a \cdot P\end{array}$ & r) $=$ & & $\frac{(\mathrm{ME}}{\left(\mathrm{P}_{50}\right)}$ & & $\frac{(\mathrm{ME})}{\left(\mathrm{P}_{50}\right)}$ & $\overline{\mathrm{P})^{\mathrm{H}}}$ \\
\hline Dose & 11.2 & $(2.1)$ & .90 & 11.4 & $(2.2)$ & .89 & 21.5 & $(3.7)$ & 13.8 & (2.6) \\
\hline $\mathrm{C}_{\max }$ & 20.0 & (3.5) & .61 & 20.1 & (3.5) & .61 & 27.1 & (4.6) & 18.8 & (3.4) \\
\hline Time above $1.0 \mathrm{nM}$ & 25.5 & (4.4) & .04 & 25.3 & (4.3) & .07 & 30.1 & $(4.6)$ & 38.6 & (6.7) \\
\hline Time above $10 \mathrm{n} M$ & 13.5 & $(2.5)$ & .84 & 14.5 & $(2.7)$ & .82 & 22.7 & (3.8) & 13.0 & (2.5) \\
\hline AUC of lactone & 20.1 & $(3.5)$ & .61 & 20.4 & (3.5) & .59 & 25.5 & $(4.2)$ & 17.5 & (3.2) \\
\hline AUC of hydroxy acid & 15.6 & $(2.9)$ & .81 & 16.1 & $(2.9)$ & .77 & 28.5 & $(6.2)$ & 18.8 & (3.6) \\
\hline Total AUC & 15.1 & $(2.8)$ & .81 & 15.8 & $(2.9)$ & .78 & 21.5 & $(3.7)$ & 13.6 & $(2.6)$ \\
\hline
\end{tabular}

nadirs of both leukocytopenia and granulocytopenia were between day 8 and 15 and were of brief duration (3-5 days). Previous chemo- and/or radiotherapy could not be identified as risk factors. There were no indications of cumulative myelotoxicity. In contrast, the extent of myelosuppression during the first course of treatment appeared to be repetitive in all subsequent courses.

\section{Non-hematological toxicity}

Nausea and vomiting were found to be non-dose-dependent and occurred in 49 courses (23\%), being classed as grade 2 or 3 in 29 courses (13\%). They were easily prevented with standard antiemetics in most patients in subsequent courses. Alopecia was also not dose-dependent and occurred in 9 patients $(19 \%)$, being total in $5(10 \%)$. Other incidental side effects were asymptomatic hypotension (35 courses, 16\%), mild proteinuria ( 8 courses, $4 \%$ ), and microscopic hematuria (6 courses, 3\%). There was no gastrointestinal, cardiac, liver, renal, or skin toxicity.

\section{Responses}

Response could be evaluated in 40 patients. A partial remission was seen in 3 female patients ( 1 with small-cell lung cancer, 1 with non-small-cell lung cancer, and 1 with metastatic pancreatic cancer with a partial remission of the liver metastases). Unfortunately, these patients did not participate in our pharmacokinetic studies. Stable disease was seen in 24 patients.

\section{Modelling pharmacokinetic-pharmacodynamic relationships}

The pharmacokinetic parameters obtained from 19 patients (i.e. the $\mathrm{C}_{\max }$, the time period above a concentration of $1.0 \mathrm{nM}$ or $10 \mathrm{nM}$ and the AUC of topotecan, the AUC of its metabolite, the total AUC, and the dose), were plotted against the percentage decrease in WBC and in ANC. Plots of the percentage decrease in ANC and in WBC versus other pharmacokinetic parameters did not yield any significant relationship.

We compared four different models for their ability to describe the data. All data were modelled using a linear, a $\log$-linear, an $\mathrm{E}_{\max }$ and a sigmoidal $\mathrm{E}_{\max }$ model [Eqs. (5), (6), (7), (8), respectively]. In general, the decrease (\%) in ANC, which was dose-limiting, showed better correlations than that in WBC (data not shown). All models predicting the decrease (\%) in WBC were more or less equally predictive: all RMSE\% values were greater than $19.3 \%$ (median $21.6 \%$, ranging to $54.8 \%$ ), and all correlation coefficients were smaller than 0.68 . The decrease (\%) in ANC appeared to be best related to the dose $\left(\mathrm{mg} \mathrm{m}^{-2} \mathrm{day}^{-1}\right)$, the total AUC, and the time period above $>10 \mathrm{n} M$ (Table 3 , Figs. 4-6). All models and comparable precision. Using the sigmE $\max$ model, the estimate for the dosage associated with $50 \%$ decrease in ANC is $0.6 \mathrm{mg} \mathrm{m}^{-2}$ day $^{-1}$. A dosage of $1.5 \mathrm{mg}$ $\mathrm{m}^{-2}$ day-1 $^{-1}$ for 5 consecutive days was considered the maximum tolerable dose (MTD) and recommended for phase II studies [30].

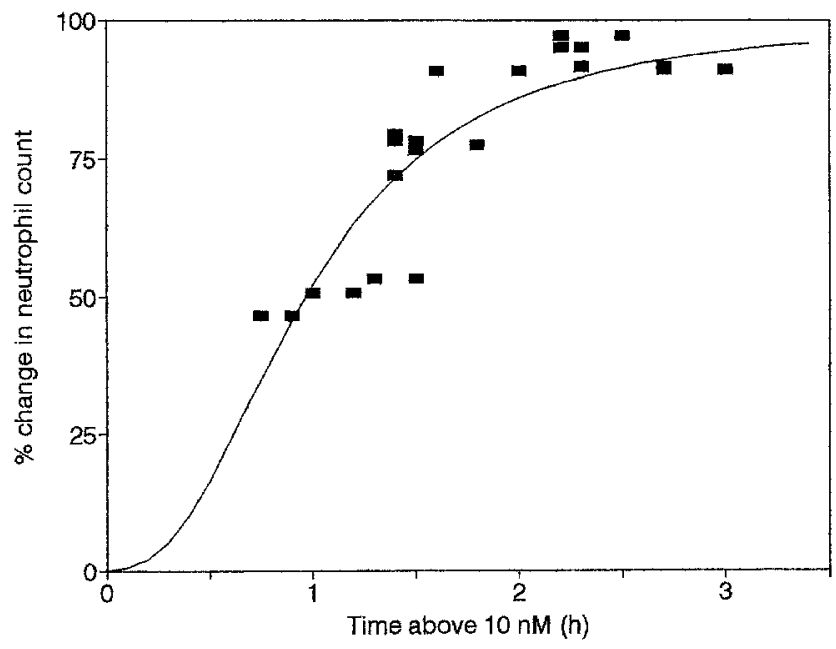

Fig. 4 Relation between the time above a concentration of $10 \mathrm{n} M$ of topotecan and the decrease (\%) in ANC. The solid line represents the fit of the data to a sigEmax model 


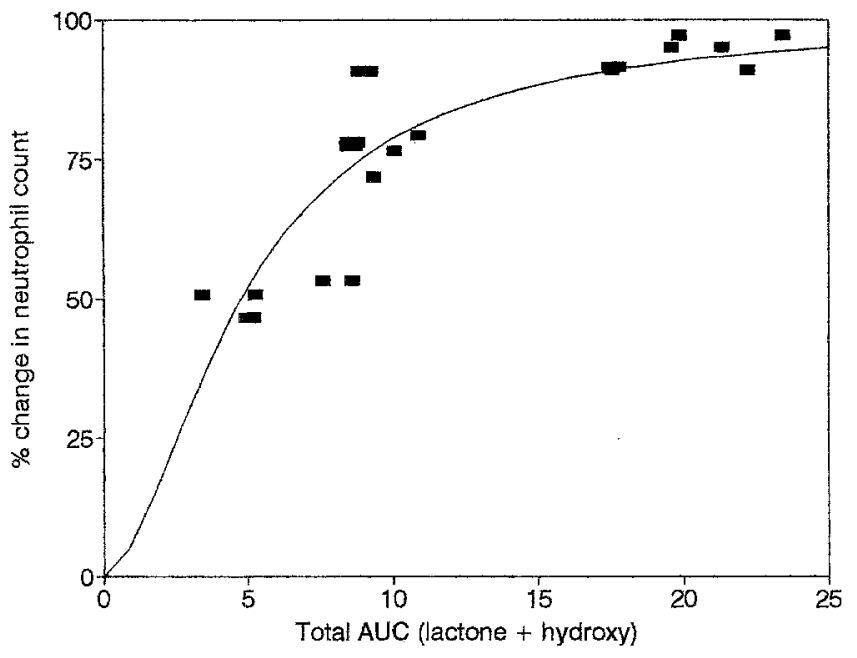

Fig. 5 Relation between the total AUC (lactone + hydroxy) and the \%decr in ANC. The solid line represents the fit of the data ot a sigE $\mathrm{max}_{\text {max }}$ model

\section{Discussion}

The chemical conversion of topotecan into the ring-opened species appeared from the start of infusion and continued until the last measured concentration (Fig. 3). The highly sensitive HPLC assay (detection limit $\approx 0.4 \mathrm{n} M$ ) allowed selective measurement of topotecan and its ring-opened form [2]. Therefore, it was possible to construct a complete pharmacokinetic curve even at the first dose step of the study. In plasma at $37^{\circ} \mathrm{C}$, no significant amount of the reverse reaction of the ring-opened form into topotecan occurs [2] and, therefore, the reversibility of the reaction has not been taken into account in the pharmacokinetic modelling. The experimental data fitted well to the models used (Eqs. 1-3), indicating that this is justified. Unlike camptothecin, topotecan does not produce hemorrhagic cystitis, despite a $26 \%$ drug excretion in the urine over the first $24 \mathrm{~h}$, and it has a reproducible and reduced toxicity profile. Compared with the $17 \%$ of camptothecin that was found in the urine after $48 \mathrm{~h}$ [8], the occurrence of hemorrhagic cystitis is most likely to be related to the improved water solubility and not the extent of urinary excretion.

The median ratio $k_{21} / k_{12}$, reflecting the return and entry of topotecan from the peripheral compartment, is 0.32 , indicating the tendency of the drug to stay behind in this compartment. Extensive binding to tissues and other components of this compartment may occur, which retards the return into the central compartment. Although this conclusion is speculative, the high value for $V_{\mathrm{ss}}$ is in agreement with extensive tissue binding in a peripheral compartment. Tissue binding may be more important than protein binding in this compartment, as the binding to human plasma proteins is only $21 \%$ [14]. The slow return into the central compartment may explain the relatively long period of time for which topotecan is detectable in plasma. The volume of distribution of the central compartment approximates that of

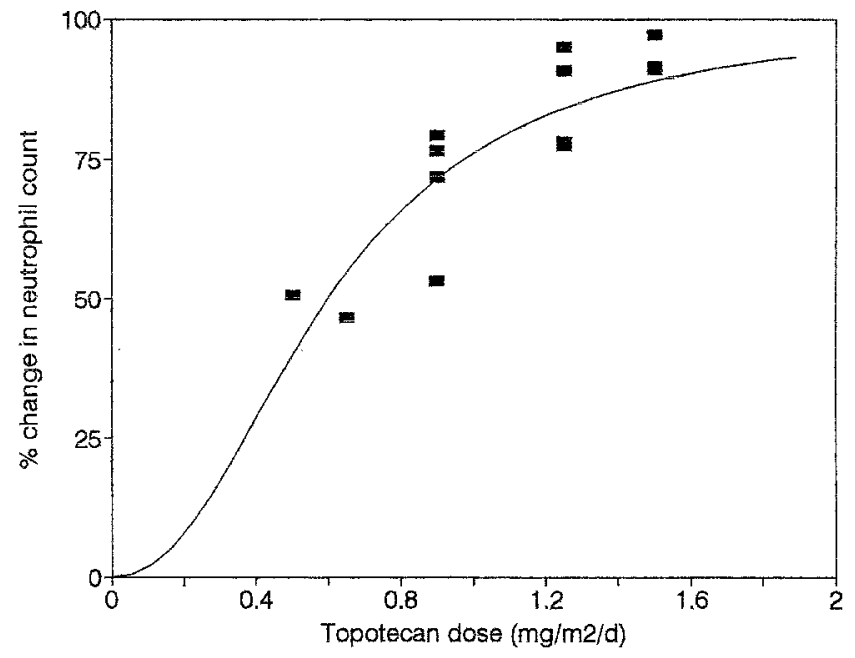

Fig. 6 Relation between the dose ( $\left.\mathrm{mg} / \mathrm{m}^{2} / \mathrm{day}\right)$ and the $\%$ decr in ANC. The solid line represents the fit of the data to a sigE $E_{\max }$ model

total body water. This compartment provides the (physiological) $\mathrm{pH}$, in which the hydrolysis reaction is continuously favored. This mechanism may determine mainly the elimination of the parent drug $\left(\mathrm{k}_{10} \approx \lambda_{\mathrm{f}}\right)$, although renal or hepatic elimination can not be excluded.

The plasma concentration versus time plots of the topotecan metabolite could be described adequately using a one-compartment model (Eq. 3). After about $1.5 \mathrm{~h}$ the concentrations of the parent drug and metabolite decline in parallel, with identical slopes. Furthermore, since the time course of the metabolite is determined by the slowest step in the sequence of formation and elimination, which is the rate of formation $\left(\lambda_{\mathrm{e}}>\lambda_{\mathrm{f}}\right)$, these data indicate that the metabolite has a shorter elimination half-life than the parent drug. Moreover, the ring-opened metabolite with a free and dissociated carboxylic function at physiological $\mathrm{pH}$ can be considered to be more highly polar and, hence, more readily and quickly eliminated from the body than the parent drug. The concentration of the metabolite in plasma might therefore be expected always to be lower than that of the parent drug. This, however, is not the case: the ratio between the plasma concentration of the parent and metabolite (Fig. 3) falls below 1 by $1 \mathrm{~h}$ after the start of infusion. A possible explanation might be the smaller volume of distribution of the metabolite, which is limited to the body water. Thus, the plasma concentrations do not reflect the total body amount of both forms. In fact, the central compartment contains about $17 \%$ of the total amount of topotecan present in the body, given by the ratio $\lambda_{2} / \mathrm{k}_{10}$. The half-life for metabolite elimination, calculated from $\lambda_{e}$, is 29.0 (range 5.6-99.5) $\mathrm{min}$, the half-life for metabolite formation, calculated from $\lambda_{\mathrm{f}}$, is 123.2 (range $32-265$ ) $\mathrm{min}$.

The pharmacodynamic-pharmacokinetic plots could be described adequately by sigmoidal $\mathrm{E}_{\max }$ models. Linear models were, generally, equally predictive, suggesting the modelling of the values of the pharmacokinetic parameters occurred in the linear part of the sigmoidal models. However, although similar results were obtained, on biological 
grounds a sigmoidal model is more obvious and, therefore, preferable. The MTD (1.5 $\mathrm{mg} \mathrm{m}^{-2}$ day $\left.^{-1}\right)$ administered in phase II studies would result in an average percentage decrease in $\mathrm{ANC}$ of $87 \%$, as predicted by the sigmE model. The estimate for $\mathrm{P}_{50}$ (the dose associated with $50 \%$ decrease in ANC) is $0.6 \mathrm{mg} \mathrm{m}^{-2}$ day $^{-1}$. This is in accordance with the findings of others $[9,22]$ (i. e. $0.8 \mathrm{mg} \mathrm{m}^{-2}$ day-1). $^{-1}$. These published pharmacodynamic studies also suggested that the relationship between the dose $\left(\mathrm{mg} \mathrm{m}^{-2}\right.$ day $\left.^{-1}\right)$ and total AUC and decrease (\%) in ANC were the only ones [9, 22]. Other relationships with pharmacokinetic parameters could not be detected. This is in contrast to the present study, where plots of percentage decrease in ANC versus the dose, the AUC of topotecan, the AUC of its metabolite, and the total AUC were quite similar. The differences found in our study as against other reports may be explained in part by the sensitive and selective measurement of both forms. In other studies the HPLC method used was selective for only the lactone (closed) form of topotecan, whereas the ringopened form was calculated as the total topotecan concentration (after sample acidification) minus the concentration of the lactone form $[5,9,26,33]$.

In conclusion, it is important that the pharmacokinetics of topotecan and its inactive metabolite are described, since this may help us to determine the optimal mode of drug administration and the optimal dosage, and extend our understanding of the differences found in pharmacodynamic outcome. Further research into the pharmacokinetic-pharmacodynamic relationships of topotecan is needed. For example, day-to-day variation within patients should be investigated, since the pharmacokinetics can vary very widely between days 1 and 4 , as noted in two of our patients. With the aid of a limited-sampling model we have recently developed [29], which requires only one plasma concentration determination, we are now performing a pharmacokinetic study in which we determine AUC values on 5 consecutive days. With this information, the pharmacokinetic-dynamic relationships will be further explored. The encouraging results of phase I and II studies [17, $20,24]$ legitimate this goal.

\section{References}

1. Anonymous (1988) DNA topoisomerases - new twists to tumour therapy. Lancet I: 512

2. Beijnen JH, Smith BR, Keijer WJ, Van Gijn R, Ten Bokkel Huinink WW, Vlasveld LT, Rodenhuis S, Underberg WJM (1990) Highperformance liquid chromatographic analysis of the new antitumour drug SK\&F 104864-A (NSC 609699) in plasma. J Pharm Biomed Anal 8: 789

3. Blaney SM, Balis FM, Cole DE, Craig C, Reid JM, Ames MM, Krailo M, Reaman G, Hammond D, Poplack DG (1993) Pediatric phase I trial and pharmacokinetic study of topotecan administered as a 24-hour continuous infusion. Cancer Res 53: 1032

4. Burris H, Kuhn J, Johnson R, Von Hoff D (1990) Preclinical studies of a new topoisomerase I inhibitor. Proc Am Assoc Clin Oncol 31: 431

5. Burris HA, Rothenberg ML, Kuhn JG, Von Hoff DD (1992) Clinical trials with the topoisomerase I inhibitors. Semin Oncol 19: 663
6. Eckhart J, Burris H, Kuhn J, Smith S, Rodriguez G, Weiss G, Smith L, Shaffer D, Johnson R, Von Hoff D (1992) Phase I and pharmacokinetic trial of continuous infusion of topotecan in patients with refractory solid tumors. Proc Am Soc Clin Oncol 11: 138

7. Gibaldi M, Perrier D (1982) Pharmacokinetics, 2nd edn. Dekker, New York Basel

8. Gottlieb JA, Guarino AM, Call JB, Oliverio VT, Block JB (1970) Preliminary pharmacologic and clinical evaluation of camptothecin sodium. Cancer Chemother Rep 54: 461

9. Grochow LB, Rowinsky EK, Johnson R, Ludeman S, Kaufmann SH, McCabe FL, Smith BR, Hurowitz L, DeLisa A, Donehower RC, Noe D (1992) Pharmacokinetics and pharmacodynamics of topotecan in patients with advanced cancer. Drug Metab Dispos 20: 706

10. Hertzberg RP, Caranfa MJ, Hecht SM (1989) On the mechanism of topoisomerase I inhibition by camptothecin: evidence for binding to an enzyme-DNA complex. Biochemistry $32: 715$

11. Hertzberg RP, Caranfa MJ, Holden KG, Jakas DR, Gallagher G, Mattern MR, Mong SM, Bartus JO, Johnson RK, Kingsbury WD (1989) Modification of the hydroxy lactone ring of camptothecin: inhibition of mammalian topoisomerase I and biological activity. J Med Chem 32: 715

12. Houghton PJ, Cheshire PJ, Myers L, Stewart CF, Synold TW, Houghtom JA (1992) Evaluation of 9-dimethylaminomethyl-10hydroxycamptothecin against xenografts derived from adult and childhood solid tumors. Cancer Chemother Pharmacol 31: 229

13. Hsiang YH, Lihou MG, Liu LF (1989) Arrest of replication forks by drug-stabilized topoisomerase I-DNA cleavable complexes as a mechanism of cell killing by camptothecin. Cancer Res 49: 5077

14. Investigators brochure (1990) Topotecan (SK\&F 104864-A). SmithKline Beecham Pharmaceuticals, Philadelphia, USA

15. Jodrell DI, Egorin MJ, Canetta RM, Langenberg P, Goldbloom EP, Burroughs JN, Goodlow JL, Tan S, Wiltshaw E (1992) Relationships between carboplatin exposure and tumor response and toxicity in patients with ovarian cancer. J Clin Oncol 10:520

16. Kantarjian HM, Beran M, Ellis A, Zwelling L, O'Brien S, Cazenave L, Koller C, Rios MB, Plunkett W, Keating M, Estey EH (1993) Phase I study of topotecan, a new topoisomerase I inhibitor, in patients with refractory or relapsed acute leukemia. Blood 81: 1146

17. Kudelka A, Edwards C, Freedman R, Wallin B, Hord M, Howell E, Harper K, Raber M, Kavanaugh J (1993) A phase II study of topotecan administered intravenously as 5 daily infusions every 21 days to women with refractory epithelial ovarian carcinoma. Eur J Cancer 29A [Suppl 6]: S132

18. Moertel CG, Schutt AJ, Reitemeier RJ, Hahn RG (1972) Phase II study of camptothecin in the treatment of advanced gastrointestinal cancer. Cancer Chemother Rep 56: 95

19. Muggia FM, Creaven PJ, Hansen H, Cohen MH, Selawry OS (1972) Phase I clinical trial of weekly and daily treatment with camptothecin: correlation with preclinical studies. Cancer Chemother Rep 56: 515

20. Perez-Soler R, Glisson BS, Kane J, Raber MN, Hong WK (1993) Phase II study of topotecan in patients with non-small cell lung cancer. Eur J Cancer 29A [Suppl 6]: S162

21. Proost JH, Meijer DKF (1992) MW/PHARM, An integrated software package for drug dosage regimen calculation and therapeutic drug monitoring. Comput Biol Med 22: 155

22. Rowinsky EK, Grochow LB, Hendriks CB, Ettinger DS, Forastiere AA, Hurowitz LA, McGuire WP, Sartorius SE, Lubejko BG, Kaufmann SH, Donehower RC (1992) Phase I and pharmacologic study of topotecan: a novel topoisomerase I inhibitor. J Clin Oncol 10: 647

23. Saltz L, Sirott M, Young C, Tong W, Niedzwiecki D, Tzy-Jyun Y, Tao Y, Trochanowski B, Wright P, Barbosa K, Toomasi F, Kelsen D (1993) Phase I clinical and pharmacology study of topotecan given daily for 5 consecutive days to patients with advanced solid tumors, with attempt at dose intensification using recombinant granulocyte colony-stimulating factor. J Natl Cancer Inst 18: 1499 
24. Scher R, Lush CJ, Green K, Kosierowski R, Simmonds M, Engstrom PF, O'Dwyer PJ (1993) Phase II trial of topotecan in advanced pancreatic cancer. Eur J Cancer 29A [Suppl 6]: S101

25. Sheiner LB, Beal SL (1981) Some suggestions for measuring predictive performance. J Pharmacokinet Biopharm 9: 503

26. Sirott MN, Saltz L, Young C, Tong W, Trochanowski B, Niedzwiecki D, Toomasi F, Kelsen D (1991) Phase I and clinical pharmacologic study of intravenous topotecan. Proc Am Assoc Clin Oncol 10: 104

27. Slichenmyer WJ, Rowinsky EK, Donehower, RC, Kaufmann SH (1993) The current status of camptothecin analogues as antitumor agents. J Natl Cancer linst 85: 271

28. Underberg WJM, Goossen RMJ, Smith BR, Beijnen JH (1990) Equilibrium kinetics of the new experimental anti-tumour compound SK\&F 104864-A in aqueous solution. J Pharm Biomed Anal 8: 681

29. Van Warmerdam LJC, Verweij J, Rosing H, Schellens JHM, Maes RAA, Beijnen JH (1994) Limited sampling models for topotecan pharmacokinetics. Ann Oncol 5: 259
30. Verweij J, Lund B, Beijnen J, Planting A, Boer-Dennert $M$ de, Koier I, Rosing H, Hansen H (1993) Phase I and pharmacokinetic study of topotecan, a new topoisomerase I inhibitor. Ann Oncol 4: 673

31. Wall ME, Wani MC (1977) Antineoplastic agents from plants. Annu Rev Pharmacol Toxicol 17: 117

32. Wall J, Burris H, Rodriguez, G, Brown T, Weiss G, Kuhn J, Brown J, Johnson R, Friedman C, Mann W, Von Hoff D (1991) Phase I trial of topotecan (SK\&F 104864) in patients with refractory solid tumors. Proc Am Assoc Clin Oncol 10: 98

33. Wall JG, Burris HA, Von Hoff DD, Rodriguez G, Kneuper-Hall R, Shaffer D, O'Rourke T, Brown T, Weiss G, Clark G, McVea $S$, Brown J, Johnson R, Friedman C, Smith B, Mann WS, Kuhn J (1992) A phase I clinical and pharmacokinetic study of the topoisomerase I inhibitor topotecan (SK\&F 104864) given as an intravenous bolus every 21 days. Anticancer Drugs 3: 337 